Blast Mitigation 

Arun Shukla - Yapa D.S. Rajapakse Mary Ellen Hynes

Editors

\section{Blast Mitigation}

Experimental and Numerical Studies

刑 Springer 


\section{Editors}

Arun Shukla

Department of Mechanical, Industrial and Systems Engineering

University of Rhode Island

Kingston, RI, USA

\author{
Mary Ellen Hynes \\ Infrastructure Protection \& Disaster \\ Management \\ Science and Technology Directorate \\ U.S. Department of Homeland Security \\ Washington, DC, USA
}

\author{
Yapa D.S. Rajapakse \\ Office of Naval Research \\ Solid Mechanics \\ Arlington, VA, USA
}

ISBN 978-1-4614-7266-7

ISBN 978-1-4614-7267-4 (eBook)

DOI 10.1007/978-1-4614-7267-4

Springer New York Heidelberg Dordrecht London

\author{
Library of Congress Control Number: 2013941355
}

(C) Springer Science+Business Media New York 2014

This work is subject to copyright. All rights are reserved by the Publisher, whether the whole or part of the material is concerned, specifically the rights of translation, reprinting, reuse of illustrations, recitation, broadcasting, reproduction on microfilms or in any other physical way, and transmission or information storage and retrieval, electronic adaptation, computer software, or by similar or dissimilar methodology now known or hereafter developed. Exempted from this legal reservation are brief excerpts in connection with reviews or scholarly analysis or material supplied specifically for the purpose of being entered and executed on a computer system, for exclusive use by the purchaser of the work. Duplication of this publication or parts thereof is permitted only under the provisions of the Copyright Law of the Publisher's location, in its current version, and permission for use must always be obtained from Springer. Permissions for use may be obtained through RightsLink at the Copyright Clearance Center. Violations are liable to prosecution under the respective Copyright Law.

The use of general descriptive names, registered names, trademarks, service marks, etc. in this publication does not imply, even in the absence of a specific statement, that such names are exempt from the relevant protective laws and regulations and therefore free for general use.

While the advice and information in this book are believed to be true and accurate at the date of publication, neither the authors nor the editors nor the publisher can accept any legal responsibility for any errors or omissions that may be made. The publisher makes no warranty, express or implied, with respect to the material contained herein.

Printed on acid-free paper

Springer is part of Springer Science+Business Media (www.springer.com) 


\section{Preface}

The aim of this book is to present a collected source of recent knowledge to graduate students and researchers working in the field of blast loadings and their effect on material and structural failure. This book covers experimental, numerical, and analytical aspects of material and structural response to dynamic blast loads and their mitigation.

Since dynamic blast loading problems are challenging, there is a paucity of mechanics- and physics-based solutions to mitigate the effect of these loadings on structures. The nation has a large, intricate, varied, yet vulnerable infrastructure system that is in turn composed of several smaller systems. The requirements to protect such a complex system and its components from a threat, including an explosive threat, can be examined in terms of systematic resiliency. Resiliency here is defined as the ability of a threatened system to prevent, sustain, and recover functionality in time, preferably very rapidly, after successful execution of the threat. Thus, a more resilient infrastructure is better able to recover from both natural and man-made disasters, is less susceptible to disruption, and is, ultimately, less attractive to attack. The material improvements for mitigation should be optimized across as wide a range of threat and vulnerability configurations as possible to improve a structural system's overall resiliency.

The idea for preparing this book originated as a result of two workshops on "Blast Mitigation" organized at the University of Rhode Island in 2009 and 2010 under the sponsorship of the Department of Homeland Security. The thrust of these workshops was in identifying areas of research, yet unexplored, and in recognizing hurdles that hinder progress in the field of blast mitigation.

The presentations at these workshops addressed various means of mitigating explosive threats through the study of composites, as well as a better understanding of construction materials, scaling, blast phenomenology, and of structural and system performance in response to blast loading. As a result of the workshop, several data gaps were identified and some are listed below

- Blast overpressure dampening by utilizing water mist or other methods.

- Development of resilient self-healing materials. 
- Understanding failure mechanisms in and developing engineering failure models for novel composite blast-resistant materials.

- Development of novel metallic and composite sandwich structures for energy absorption and structural integrity under blast loading.

- Understanding structural collapse mechanisms, including the effect of elevated temperatures on structural steel, and developing numerical codes to predict structural collapse.

- Understanding key material attributes that improve the response of structures under simultaneous blast and fragment impact.

- Understanding the shattering of glass and developing glass that is both blast resistant and energy efficient.

- Understanding stress wave scattering and attenuation due to particulates for better dampening and channeling of energy.

- Addressing scaling issues to take lab experiments to full scale.

- Development of expendable or sacrificial shields.

- Development of active shielding systems, including triggering through radio frequency broadcast.

The book consists of 11 chapters from leading researchers in the world and broadly covers the field of blast mitigation. It includes chapters on dampening of blast overpressure, energy absorption, and reflection from structures during blast loading, fluid-structure interaction, structural collapse during post-blast and design of novel and better structural configurations. The topic of implosion during blast loading is also discussed. In addition, the structural and material response to air blast as well as underwater blast is addressed.

This book would not have been possible without the timely cooperation of the authors of the chapters contained in this book, and we want to thank them for their contributions. The editors thank the staff at Springer for their exemplary help, patience, and understanding in bringing this book to fruition. The help of Mr. Nicholas Heeder, Mr. Sachin Gupta, and Mr. Frank LiVolsi in proofreading the manuscript is gratefully acknowledged. Finally, we would like to note that the proceeds from this book will go to the educational fund of the Society for Experimental Mechanics (SEM) to help in encouraging students to pursue research in experimental mechanics, which has much to contribute to the society.

Kingston, RI, USA

Arlington, VA, USA

Washington, DC, USA
Arun Shukla

Yapa D.S. Rajapakse Mary Ellen Hynes 


\section{Contents}

1 Experimental Investigation of Blast Mitigation

for Target Protection

S.F. Son, A.J. Zakrajsek, E.J. Miklaszewski, D.E. Kittell,

J.L. Wagner, and D.R. Guildenbecher

2 Application of High Performance Computing to Rapid Assessment of Tunnel Vulnerability to Explosive Blast and Mitigation Strategies

L. Glascoe and T. Antoun

3 Numerical Analysis of the Response of Biomimetic

Cellular Materials Under Static and Dynamic Loadings

Ashkan Vaziri and Ranajay Ghosh

4 Experimental and Theoretical Studies of

Fiber-Reinforced Composite Panels Subjected

to Underwater Blast Loading.

Xiaoding Wei and Horacio D. Espinosa

5 Underwater Explosive Response of Submerged, Air-backed Composite Materials: Experimental and Computational Studies

James LeBlanc and Arun Shukla

6 Underwater Implosion Mechanics: Experimental and Computational Overview

James LeBlanc, J. Ambrico, and S. Turner

7 Dynamic Buckling and Fluid-Structure Interaction of Submerged Tubular Structures

Neal P. Bitter and Joseph E. Shepherd 
8 The Use of Tubular Structures as Cores for Sandwich Panels Subjected to Dynamic and Blast Loading: A Current "State of the Art"

S. Chung Kim Yuen and G.N. Nurick

9 Mitigation of Loading on Personnel in

Light-Armored Vehicles Using Small Model Testing.

Thomas Brodrick, Ryan Hurley, and W.L. Fourney

10 Blast Response of Sandwich Composites: Effect of Core

Gradation, Pre-loading, and Temperature

N. Gardner, S. Gupta, E. Wang, and Arun Shukla

11 Progressive Collapse Resistance of Reinforced

Concrete Structures

M. Sasani

Index 